\title{
Frequency of Placenta Previa and Maternal Morbidity Associated with Previous Cesarean Delivery*
}

\author{
Anisodowleh Nankali ${ }^{1 \#,}$, Farahnaz Keshavarzi' ${ }^{1}$, Atefeh Shajari' ${ }^{1}$, Sara Daeichin ${ }^{2}$ \\ ${ }^{1}$ Kermanshah University of Medical Sciences, Kermanshah, Iran \\ ${ }^{2}$ MSc Student in Obstetrics, Students Research Committee, School of Nursing and Midwifery, Kermanshah \\ University of Medical Sciences, Kermanshah, Iran \\ Email: "anis nankali@yahoo.com
}

Received 17 August 2014; revised 15 September 2014; accepted 8 October 2014

Copyright (C) 2014 by authors and Scientific Research Publishing Inc.

This work is licensed under the Creative Commons Attribution International License (CC BY).

http://creativecommons.org/licenses/by/4.0/

c) (i) Open Access

\section{Abstract}

Background: Placenta previa (P.P) is a rare pregnancy complication where a placenta particularly or completely covers the internal cervical os thereby preventing normal vaginal delivery. This study was conducted to evaluate the relationship between repeated cesarean deliveries and subsequent development of placenta previa. Methods \& Materials: This cross-sectional study was held in Imam Reza Hospital Kermanshah-Iran during 2008-2011. This study included all pregnant women with repeated cesarean sections while nullipara and patients with placenta previa without previous surgery were excluded. Diagnosis was made on ultrasound and at surgery. Results: among 2696 Women, 98 cases had P.P (3.63\%). The mean age was 30 years, $76.5 \%$ (75 cases) had gravidity 2 and 3 and $87.8 \%$ (86 cases) had parity $1-3$. Anterior location of placenta was $44.9 \%$ while posterior was $55.1 \%$. $48 \%$ were complete P.P, $32.7 \%$ low lying P.P, $13.3 \%$ marginal P.P, and 6\% Partial P.P. 26.5\% of patients had history of abortion. 55.1\% of patients had male fetus. There was an increase in frequency of placenta previa with just one previous C-section (74.5\%). Frequency of accreta P.P $32 \%(n=7)$, increta $(14.3 \%, n=3)$ and percreta $28 \%(n=6)$. Among those who underwent emergency hysterectomy ( 21 cases) $23.8 \%$ cases had no abnormal placentation. $30.6 \%$ of newborns had birth weight $<2500 \mathrm{~g}$. Conclusion: we concluded that patients with history of one pervious cesarean delivery had more Placenta previa and need to hysterectomy were more than those with history of 2 and 3 previous cesarean delivery. The most common type of abnormal placentation was accreta, percreta and increta respectively.

\footnotetext{
*This work was performed in partial fulfillment of the requirements for (M.D.) of Atefeh Shajari of Kermanshah University of Medical Sciences. "Corresponding author.
} 


\section{Keywords}

\section{Placenta Previa, Cesarean, Maternal Morbidity}

\section{Introduction}

Placenta previa (P.P) is a rare pregnancy complication where a placenta particularly or completely covers the internal cervical os thereby preventing normal vaginal delivery [1]. It is found to complicate $0.3 \%-0.8 \%$ of all pregnancies worldwide [2]-[7]. Risk factors for (P.P) include previous uterine scar, smoking, maternal age over 35 years, grand multipaity, recurrent abortions, low socioeconomic status, infertility treatment and male gender. P.P is also associated with abnormal placentation and preterm delivery [8]-[11]. The higher incidence of cesarean delivery today is strongly associated with the greater frequency of P.P from 1/10,000 pregnancies in 1950 to $1 / 200$ frequencies nowadays [12]. The risk of morbidity adherent placenta, a life-threatening condition increases with each previous cesarean birth [13]. Nulliparous women with a P.P have a 1\% - 3\% rise in contrast with 2 or more previous deliveries who have a P.P the risk increases to $30 \%-51 \%$ [14]. The authors of one study found that in the presence of a P.P the risk of placenta accreta was $3 \%, 40 \%, 61 \%$ and $67 \%$ for the first, second, third, fourth, and fifth or greater repeat cesarean deliveries, respectively [15].

This markedly increases risk for massive hemorrhage at the time of attempted placental removal and it is the most common indication for emergency hysterectomy. The maternal mortality risk may reach $7 \%$ and surgically morbidities include massive transfusion, infection, urologic injuries and fistula for mation [16].

History and number of previous cesarean delivery is important to have placenta previa and abnormal placentation in subsequent pregnancies. Imam Reza teaching hospital is a referral center in the west of Iran and most of repeated cesarean deliveries are done in our institution and today we face with many patients with placenta previa who need hysterectomy, So we decided to conduct this study to evaluate the frequency of the placenta previa and morbidity adherent P.P based on number of previous cesarean deliveries.

\section{Methods \& Materials}

This cross sectional, observational study was conducted in the department of obstetrics \& gynecology at Imam Reza teaching hospital Kermanshah medical college from end of 2008 to end of 2011. It was approved by Clinical Research Development Center, Imam Reza Hospital. Kermanshah University of Medical Sciences (KUMS), name and private information of patient was kept secret. This study included all pregnant women with repeated cesarean sections while nullipara and patients with placenta previa without previous surgery were excluded. Based on the review of medical database data was collected regarding maternal age, parity, gravidity, gestational age, number of previous cesarean deliveries, grade of P.P, location of placenta anterior versus posterior, abortion, abnormal placentation, fetal sex, fetal anomalies recorded on the specially designed performa. Birth weight, Apgar score, need to hysterectomy were also considered. Diagnosis was made on ultrasound and at surgery. All grades of P.P were included the study. A total number of 2696 patients with history of previous C-section during 4 years were enrolled for the study purpose .finally data was analyzed by SPSS software version 18 .

\section{Results}

During 2008-2011, 2696 patients with history of previous cesarean delivery were recorded at Imam Reza teaching hospital, among them 98 patients had P.P with frequency of 3.63\% (Table 1).

Anterior location of placenta was determined in 44 cases (44.9\%) and posterior location in 54 cases (55.1\%). regarding type of P.P 48\% were complete P.P, 32.7\% low lying P.P, $13.3 \%$ marginal P.P, and 6\% Partial P.P. in those with history of previous cesarean section and P.P, the mean age was 30 years old, $76.5 \%$ (75 cases) had gravidity 2 and 3 and 87.8\% (86 cases) had parity 1 - 3. 81.8\% of patients (86 cases) had parity 1 to 3 and 12.2\% (12 cases had parity more than 3 ) mean of gestational age was 34 weeks and 6 days (Table 2).

Regarding abortion rate 36 out of 98 patients (26.5\%) had history of abortion. $55.1 \%$ of patients had male fetus and remaining $44.9 \%$ had female fetus (Figure 1).

Regarding birth weight 30.6 of newborns were low birth weight (less than $2500 \mathrm{~g}$ ). We found no congenital 
malformations in newborns.

Among those who underwent emergency hysterectomy (21 cases) 23.8\% cases had no abnormal placentation (Table 3).

In this study $22.4 \%$ of patients needed to transfusion (Table 4 ).

Table 1. Outlines the frequency of P.P by previous cesarean delivery.

\begin{tabular}{ccc|}
\hline \multirow{2}{*}{$\begin{array}{c}\text { Number of previous } \\
\text { cesarean delivery }\end{array}$} & \multicolumn{2}{c|}{ Frequency of P.P } \\
\cline { 2 - 3 } & Number & Percent \\
\hline 1 & 73 & $74.5 \%$ \\
3 & 20 & $20.4 \%$ \\
Total & 5 & $5.1 \%$ \\
\hline
\end{tabular}

Table 2. Out lines frequency of abnormal placentation in the patients.

\begin{tabular}{ccc}
\hline Abnormal placentation & Number & Frequency percent \\
\hline Accreta & 10 & $10.2 \%$ \\
Increta & 9 & $9.2 \%$ \\
Percreta & 12 & $12.2 \%$ \\
\hline
\end{tabular}

Table 3. Outlines frequency of hysterectomy based on number of previous cesarean deliveries.

\begin{tabular}{ccc}
\hline Number of cesareans & Number of hysterectomy & Percent \\
\hline 1 & 10 & 47.6 \\
2 & 8 & 38.2 \\
3 & 3 & 14.2 \\
\hline
\end{tabular}

Table 4. Shows frequency of type of abnormal placentation among hysterectomies patients.

\begin{tabular}{ccc}
\hline Type of abnormal placentation & \multicolumn{2}{c}{ Frequency of hysterectomy } \\
\hline Accreta & Number percent & $7(32 \%)$ \\
Increta & Number percent & $3(14.3 \%)$ \\
Percreta & Number percent & $6(28 \%)$ \\
\hline
\end{tabular}

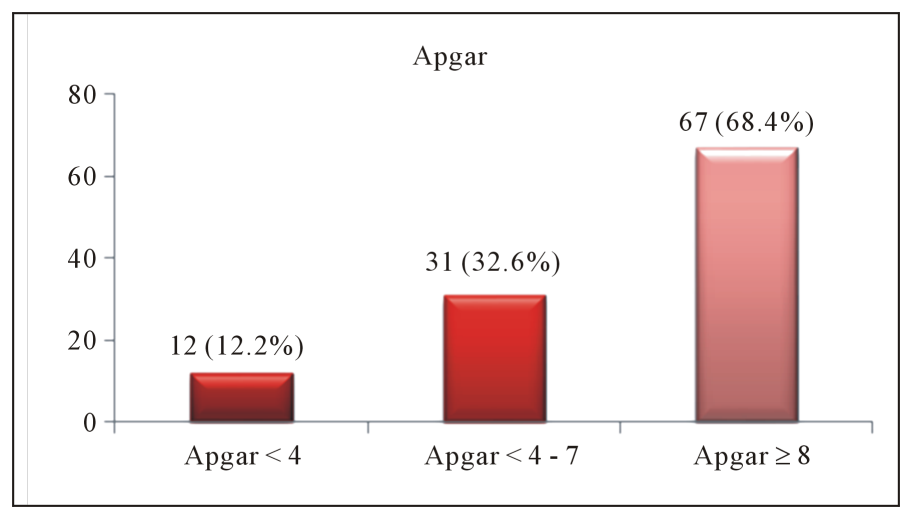

Figure 1. Outlines frequency of Apgar score in newborns. 


\section{Discussion}

The frequency of cesarean section is increasing, worldwide with a parallel rise in maternal mortality and mortality. The higher incidence of cesarean delivery today is strongly associated with greater frequency of P.P. The incidence of morbidity adherent placenta has increased dramatically over the last 3 decades with the increased in cesarean delivery rate [17]. In the present study 98 out of 2696 cases with history of cesarean delivery had P.P. Many studies conducted around the world confirm a 2 to 5 fold increase risk of placenta previa with previous history of C-section [18]-[20]. Showing up to 37.5\% increased risk with previous C-section. Present study shows the association of P.P with previous C-section (3.63\%), this can be explained by the fact that scars of C-section give a more feasible site for the placement of placenta but we didn't found any association with increasing number of C-section. $74.5 \%$ with previous $1,20.4 \%$ with previous 2 , and $5 \%$ with previous 3 . This is against finding of the study of AYESHA SHAOKAT [21] who found that the risk of P.P increases with increasing number of C-section and other studies [19] [22].

There is increased risk of abnormal adherence of placenta in women with placenta previa and previous C-section. Studies show that Placenta accreta occurs in approximately 1:1000 deliveries with a reported range from $0.04 \%$ rising up to $0.9 \%$. [20]. Our study showed 31 out of 98 patients (31.6\%) with abnormal adherence of placenta.

Another study Found 48.5\% abnormal adherence [21]. In the present study the most common type of abnormal adherence was Increta, $10.2 \%$ was accreta while SHAOKAT found 27.2\% were accreta which is more than two fold in compare to our study [21].

In the present study $48 \%$ of our patients had complete placenta previa and the second most common was low lying P.P (32.7\%).

Marginal P.P and partial P.P were the third and fourth common type, this is similar to other studies [21] [23].

According to our study $23.5 \%$ women with P.P are gravid > 3 while SHAOKAT found $60.6 \%$ women with P.P are gravid $>5[21]$.

In the present study the mean age of patients was 30 years and the mean gestational age was $34 \mathrm{w}+6$ days. History of previous abortion was $26.5 \%$. In other studies the percentages of previous abortion were significantly higher in women with P.P [24] [25]. The increase male baby incidence with P.P has been found in our study which is accordance with previous studies [21] [23] [26] and [27]. We didn't find any fetal anomaly in this study. Ananth CV conclude that there is a strong association between having a previous C-section delivery, spontaneous or induce abortion. In the study of SHAOKAT $48.8 \%$ of women had previous history of abortion and D\&C. [21] [28].

Regarding the maternal complications, 21 out of total 98 patients underwent hysterectomy and 16 out of total 21 hysterectomies patients had abnormal adherence of placenta. 33\% (7 cases) had accreta, 14.2\% (3 cases) had Increta and 28\% (6 cases) had percreta.

\section{Conclusion}

Findings of this study showed that frequency of placenta previa was 3.63\% among patients with history of pervious cesarean delivery. $74.5 \%$ of patients with placenta previa had history of one previous C-section and the rate of the need for hysterectomy in these patients was $47.6 \%$. The most common type of abnormal placentation was accreta, percreta and increta respectively.

\section{References}

[1] Cunningham, G., Leveno, K.L., Bloom, S.L., Hauth, J.C., Gilstrap III, L.C. and Wenstrom, K.D. (2005) Williams Obstetrics. 22nd Edition, McGraw-Hill, New York.

[2] Tuzovic, L., Djelmis, J. and Ilijic, M. (2003) Obstetric Risk Factors Associated with Placenta Previa Development: Case-Control Study. Croatian Medical Journal, 44, 728-733.

[3] Dola, C.P., Garite, T.J., Dowling, D.D., Friend, D., Ahdoot, D. and Asrat, T. (2003) Placenta Previa: Does Its Type Affect Pregnancy Outcome? American Journal of Perinatology, 20, 353-360. http://dx.doi.org/10.1055/s-2003-45282

[4] Gorodeski, I.G. and Bahari, C.M. (1987) The Effect of Placenta Previa Localization upon Maternal and Fetal-Neonatal Outcome. Journal of Perinatal Medicine, 15, 169-177. http://dx.doi.org/10.1515/jpme.1987.15.2.169

[5] Love, C.D. and Wallace, E.M. (1996) Pregnancies Complicated by Placenta Praevia: What Is Appropriate Management? 
BJOG: An International Journal of Obstetrics \& Gynaecology, 103, 864-867. http://dx.doi.org/10.1111/j.1471-0528.1996.tb09903.x

[6] Wehrum, M.J., Buhimschi, I.A., Salafia, C., Thung, S., Bahtiyar, M.O., Werner, E.F., et al. (2011) Accreta Complicating Complete Placenta Previa Is Characterized by Reduced Systemic Levels of Vascular Endothelial Growth Factor and by Epithelial-to-Mesenchymal Transition of the Invasive Trophoblast. American Journal of Obstetrics \& Gynecology, 204, 411.e1-.e11.

[7] Frederiksen, M.C., Glassenberg, R. and Stika, C.S. (1999) Placenta Previa: A 22-Year Analysis. American Journal of Obstetrics \& Gynecology, 180, 1432-1437. http://dx.doi.org/10.1016/S0002-9378(99)70031-1

[8] Singh, P.M., Rodrigues, C. and Gupta, A.N. (1981) Placenta Previa and Previous Cesarean Section. Acta Obstetricia et Gynecologica Scandinavica, 60, 367-368. http://dx.doi.org/10.3109/00016348109154125

[9] To, W.W. and Leung, W.C. (1995) Placenta Previa and Previous Cesarean Section. International Journal of Gynecology and Obstetrics, 51, 25-31. http://dx.doi.org/10.1016/0020-7292(95)80004-V

[10] Sheiner, E., Shoham-Vardi, I., Hallak, M., Hershkowitz, R., Katz, M. and Mazor, M. (2001) Placenta Previa: Obstetric Risk Factors and Pregnancy Outcome. Journal of Maternal-Fetal and Neonatal Medicine, 10, 414-419. http://dx.doi.org/10.1080/jmf.10.6.414.419

[11] Demissie, K., Breckenridge, M.B., Joseph, L. and Rhoads, G.G. (1999) Placenta Previa: Preponderance of Male Sex at Birth. American Journal of Epidemiology, 149, 824-830. http://dx.doi.org/10.1093/oxfordjournals.aje.a009898

[12] Plascencia, J.L., Ochoa, F.I., Zuniga, M.A. and Karchmer, S. (1995) [Placenta Praevia/Accreta and Previous Cesarean Section. Experience of Five Years at the Mexico National Institute of Perinatalogy]. Ginecología y Obstetricia de México, 63, 337-340.

[13] Lavary, S.P. (1990) Placenta Previa. Clinical Obstetrics and Gynecology, 33, 414.

[14] Miller, D.A., Chollet, J.A. and Goodwin, T.M. (1997) Clinical Risk Factors for Placenta Previa-Placenta Accreta. American Journal of Obstetrics \& Gynecology, 177, 210-214. http://dx.doi.org/10.1016/S0002-9378(97)70463-0

[15] Zhang, J. and Savitz, D.A. (1993) Maternal Age and Placenta Previa: A Population-Based, Case-Control Study. American Journal of Obstetrics \& Gynecology, 168, 641-645. http://dx.doi.org/10.1016/0002-9378(93)90511-G

[16] O’Brien, J.M., Barton, J.R. and Donaldson, E.S. (1996) The Management of Placenta Percreta: Conservative and Operative Strategies. American Journal of Obstetrics \& Gynecology, 175, 1632-1638. http://dx.doi.org/10.1016/S0002-9378(96)70117-5

[17] Warshak, C.R., Eskander, R., Hull, A.D., Scioscia, A.L., Mattrey, R.F., Benirschke, K., et al. (2006) Accuracy of Ultrasonography and Magnetic Resonance Imaging in the Diagnosis of Placenta Accreta. Obstetrics \& Gynecology, 108, 573-581. http://dx.doi.org/10.1097/01.AOG.0000233155.62906.6d

[18] Getahun, D., Oyelese, Y., Salihu, H.M. and Ananth, C.V. (2006) Previous Cesarean Delivery and Risks of Placenta Previa and Placental Abruption. Obstetrics \& Gynecology, 107, 771-778. http://dx.doi.org/10.1097/01.AOG.0000206182.63788.80

[19] Hendricks, M.S., Chow, Y.H., Bhagavath, B. and Singh, K. (1999) Previous Cesarean Section and Abortion as Risk Factors for Developing Placenta Previa. Journal of Obstetrics and Gynaecology Research, 25, 137-142. http://dx.doi.org/10.1111/j.1447-0756.1999.tb01136.x

[20] Garmi, G. and Salim, R. (2012) Epidemiology, Etiology, Diagnosis, and Management of Placenta Accreta. Obstetrics and Gynecology International, 2012, Article ID: 873929.

[21] Ayesha, S., Fareed, Z. and Samina, A. (2009) Frequency of Placenta Previa with Previous C-Section. Pakistan Journal of Medical \& Health Sciences, 16, 2.

[22] Silver, R.M., Landon, M.B., Rouse, D.J., Leveno, K.J., Spong, C.Y., Thom, E.A., et al. (2006) Maternal Morbidity Associated with Multiple Repeat Cesarean Deliveries. Obstetrics and Gynecology, 107, 1226-1232. http://dx.doi.org/10.1097/01.AOG.0000219750.79480.84

[23] Nasreen, F. (2011) Incidence, Causes and Outcome of Placenta Previa. Journal of Postgraduate Medical Institute (Peshawar-Pakistan), 17, 99-104.

[24] Taipale, P., Hiilesmaa, V. and Ylostalo, P. (1998) Transvaginal Ultrasonography at 18-23 Weeks in Predicting Placenta Previa at Delivery. Ultrasound in Obstetrics \& Gynecology, 12, 422-425. http://dx.doi.org/10.1046/j.1469-0705.1998.12060422.x

[25] Rasmussen, S., Albrechtsen, S. and Dalaker, K. (2000) Obstetric History and the Risk of Placenta Previa. Acta Obstetricia et Gynecologica Scandinavica, 79, 502-507.

[26] Daood, S., kazeem, P. and Sepideh, E. (2008) Selcted Pregnancy Variablesi Women with Placenta Previa. Research Journal of Obstetrics and Gynecology, 1, 1-5.

[27] Wen, S.W., Demissie, K., Liu, S., Marcoux, S. and Kramer, M.S. (2000) Placenta Praevia and Male Sex at Birth: Re- 
sults from a Population-Based Study. Paediatric and Perinatal Epidemiology, 14, 300-304. http://dx.doi.org/10.1046/j.1365-3016.2000.00280.x

[28] Ananth, C.V, Smulian, J.C. and Vintzileos, A.M. (1997) The Association of Placenta Previa with History of Cesarean Delivery and Abortion: A Metaanalysis. American Journal of Obstetrics \& Gynecology, 177, 1071-1078.

http://dx.doi.org/10.1016/S0002-9378(97)70017-6 
Scientific Research Publishing (SCIRP) is one of the largest Open Access journal publishers. It is currently publishing more than 200 open access, online, peer-reviewed journals covering a wide range of academic disciplines. SCIRP serves the worldwide academic communities and contributes to the progress and application of science with its publication.

Other selected journals from SCIRP are listed as below. Submit your manuscript to us via either submit@scirp.org or Online Submission Portal.
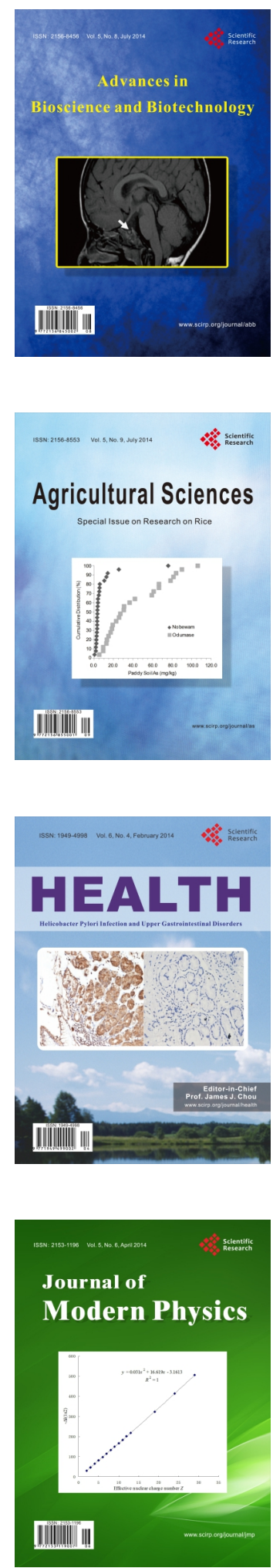
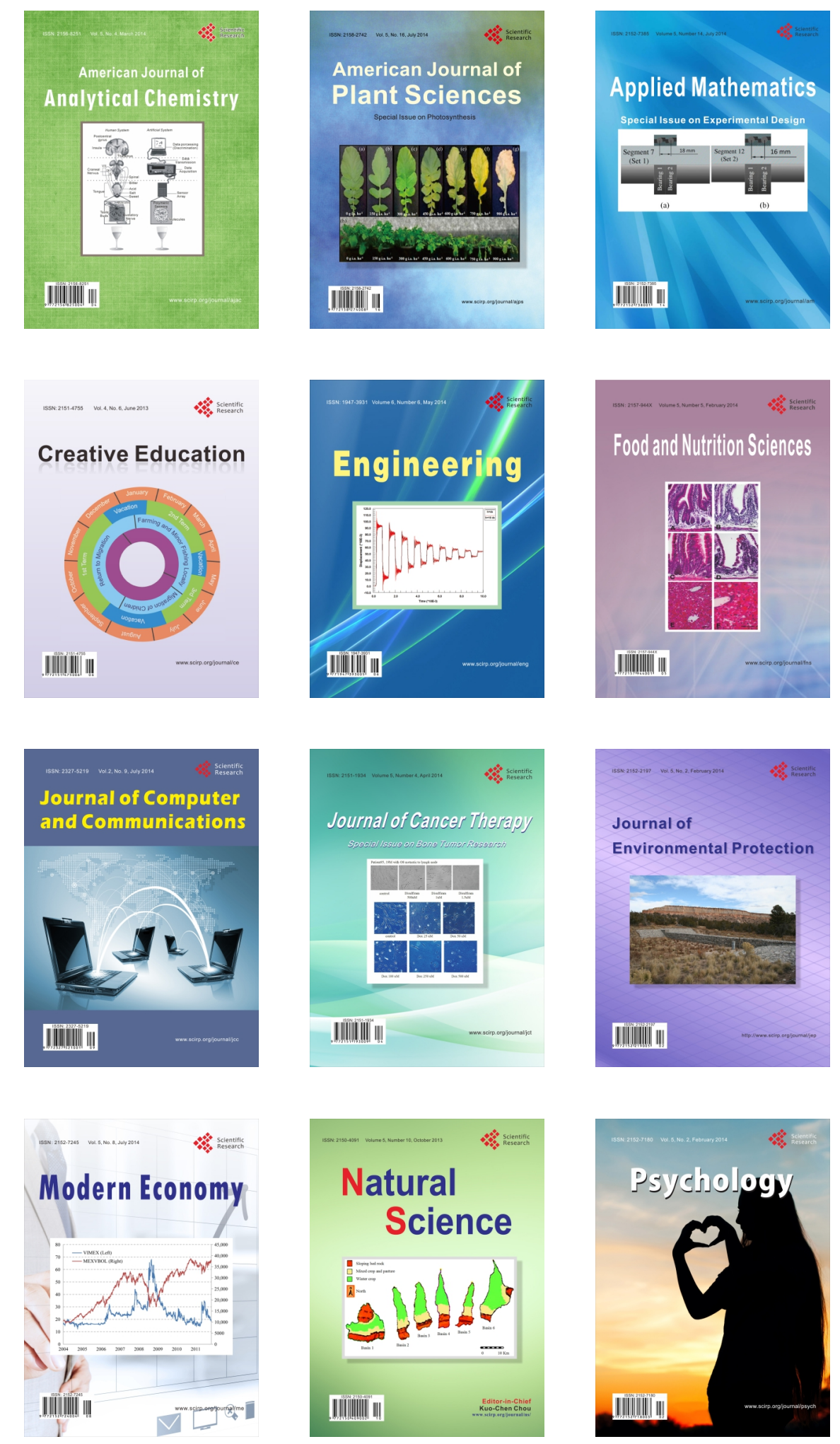